\title{
Chronic Obstructive Pulmonary Disease In
}

\section{Aboriginal Patients Of The Northern Territory Of Australia: A Landscape Perspective}

This article was published in the following Dove Press journal:

International Journal of Chronic Obstructive Pulmonary Disease

\author{
Subash S Heraganahally (D) $^{1-4}$ \\ Sanjiwika L Wasgewatta' \\ Kelly McNamara $\mathbb{D}^{2,3}$ \\ Carla C Eisemberg $\mathbb{D}^{5}$ \\ Richard C Budd' \\ Sumit Mehra $\mathbb{D}^{1,3,6}$ \\ Dimitar Sajkov 2,6,7
}

'Respiratory and Sleep Medicine, Royal Darwin Hospital, Darwin, NT, Australia; ${ }^{2}$ Flinders University - College of Medicine and Public Health, Adelaide, SA, Australia; ${ }^{3}$ Northern Territory Medical School, Charles Darwin University, Darwin, NT, Australia; ${ }^{4}$ Darwin Respiratory and Sleep Health, Darwin, NT, Australia; ${ }^{5}$ Research Institute for the Environment and Livelihoods, Charles Darwin University, Darwin, NT, Australia; ${ }^{6}$ Respiratory and Sleep Medicine, Flinders Medical Centre, Adelaide, SA, Australia;

${ }^{7}$ Australian Respiratory and Sleep Medicine Institute, Adelaide, SA,

Australia
Correspondence: Subash S Heraganahally Department of Respiratory and Sleep Medicine, Royal Darwin Hospital, I05, Rocklands Drive, Tiwi, Darwin, NT. Australia

Tel +6I-8-89228888,

Fax+6I-8-89206309

Email hssubhashcmc@hotmail.com
Background: The Aboriginal population of Australia has a higher burden of chronic health conditions than non-Aboriginal Australians. However, there is a paucity of data on clinical and demographic characteristics of chronic obstructive pulmonary disease (COPD) in this population.

Method: In this retrospective study we evaluated the clinical, demographic and environmental influences in adult Aboriginal patients with COPD living in the regional and remote communities of the Northern Territory of Australia.

Results: There were 380 patients (49\%) with a diagnosis of COPD of the 767 patients referred to specialist respiratory outreach clinics. The mean age was 57 years $(56 \%$ were female) and mean \pm SD BMI was $24.30 \pm 7.01 \mathrm{~kg} / \mathrm{m}^{2}$. Smoking history was noted in $93 \%$ of the study cohort. The most common respiratory symptom was shortness of breath in $62 \%$, and inhaled medications (salbutamol, tiotropium, salmeterol/fluticasone) were used by $79 \%$, $44 \%$ and $58 \%$ of patients, respectively. Spirometry showed obstructive impairment $\left(\mathrm{FEV}_{1} /\right.$ FVC <0.7) in $79 \%(0.56 \pm 0.17)$, with mean $\mathrm{FEV}_{1} 42 \%$ of predicted, and a bronchodilator response was present in $28.6 \%$. Comorbid bronchiectasis was diagnosed in $49.8 \%$ along with COPD. The relationship between COPD and community demography showed a higher proportion of smokers and those with underlying bronchiectasis to have lower $\mathrm{FEV}_{1} / \mathrm{FVC}$ ratios. Communities with a higher proportion of asthma were younger and had higher smoking rates. Mortality increased with increasing number of exacerbations and hospital admissions.

Conclusion: The Aboriginal population with COPD has a higher prevalence of smoking, moderate to severe airflow obstruction on spirometry and frequently co-diagnosed bronchiectasis with increased severity of ventilatory impairment.

Keywords: Aboriginal, bronchiectasis, chronic obstructive pulmonary disease, Indigenous, spirometry

\section{Plain Language Summary}

One of the most common respiratory conditions noted around the world is chronic obstructive airway disease secondary to smoking. Chronic health conditions including respiratory disorders are increasingly being noted in Aboriginal and Indigenous populations around the world. However, there are no well-documented data in the literature on Australian Aboriginal populations suffering from chronic obstructive lung disease. In this study we report the clinical and demographic characteristics and environmental influences of Aboriginal patients diagnosed with chronic obstructive pulmonary disease living in the regional and remote communities of the Northern Territory of Australia. Our study showed that smoking rates are 
higher in this population, along with reduced lung function, and patients are symptomatic owing to the underlying respiratory condition. Moreover, the presence of other respiratory conditions such as bronchiectasis was noted in a high number of patients, and when coexisting with smoking-related lung disease the lung function was worse.

\section{Introduction}

Chronic obstructive pulmonary disease (COPD) is one of the major causes of morbidity and mortality and is the third most common cause of death worldwide. ${ }^{1-4}$ In Australia, about $4 \%$ of mortality is attributed to COPD. The prevalence of COPD increases rapidly with age and, therefore, it is more commonly diagnosed in the elderly population. ${ }^{5}$ The burden of chronic health conditions, including COPD, is higher in the Aboriginal population compared to the non-Aboriginal population, and more so in those living in remote and regional communities. ${ }^{6-8}$ The BOLD Australian study, which included a proportion $(3.3 \%)$ of Aboriginal Australians, estimated the Australian national prevalence of COPD to be around 7.5\%. ${ }^{9}$ Surveys of hospital admission and mortality data show that a higher burden of disease is attributable to COPD in the Aboriginal population in Australia. ${ }^{10}$ Factors contributing to the development of COPD in Aboriginal people may vary; however, tobacco smoking is twice as common among Indigenous compared to nonIndigenous people and the highest smoking rates in Australia are recorded in the remote Aboriginal communities of the Northern Territory (NT). ${ }^{11}$ Our 2017 study demonstrated that smoking was highly prevalent among Aboriginal people living in remote and regional communities compared to non-Aboriginal people, and higher rates of COPD were noted in Aboriginal patients (56\%) compared to non-Aboriginal patients $(28 \%) .{ }^{12}$ Furthermore, Aboriginal people living in remote and regional communities are also exposed to a significant amount of environmental smoke due to frequent fires in the surrounding savanna. ${ }^{13-16}$ It is likely that environmental smoke exposure contributes to respiratory illness or gives rise to exacerbations of symptoms secondary to underlying COPD. Nevertheless, even though COPD appears to be more prevalent in the Australian Aboriginal population, there is a paucity of data regarding the clinical characteristics and severity of COPD in this population.

Thirty per cent of the NT population is of Aboriginal origin and the majority of them live in remote and regional communities. Efforts to better understand the clinical characteristics of COPD in order to implement appropriate intervention strategies are crucial to reduce the morbidity and mortality in this population. Therefore, in this retrospective study, we documented the clinical, demographic and environmental influences in Aboriginal adult patients with a clinical diagnosis of COPD living in remote and regional communities who were referred to the Top End Health Service (TEHS), Royal Darwin Hospital, specialist respiratory outreach team.

\section{Method}

\section{Background And Setting}

This is a 5-year retrospective study (2012-2016) of all adult Australian Aboriginal patients with a diagnosis of COPD. Only patients from the regional and remote communities of the Top End NT of Australia referred to the specialist respiratory outreach team were included in this study. The TEHS map is shown in Figure 1. The specialist respiratory outreach team based at the Royal Darwin Hospital visits an average of about 20 remote communities each year at a frequency of one to three times per year. Over the 5-year period, there were approximately over 112 outreach visits to the remote communities. The average population in each community can vary anywhere between 200 and 2000 and the majority of them are of Indigenous origin. The distance from the metropolitan capital Darwin City to the remote community ranged from 100 to $1000 \mathrm{~km}$.

For the purpose of this study, "COPD" implies a primary diagnosis of COPD, and the coexistence of asthma or bronchiectasis was considered as a secondary diagnosis when present, irrespective of severity. In this study the wording "Aboriginal" and "Indigenous" represents native original Indigenous people by descent.

\section{Clinical Parameters}

Patients' clinical details were extracted from medical records, including demographics, smoking status, body mass index (BMI), COPD-directed therapy, comorbidities, mortality and relevant investigations. The investigations extracted for this study included pulmonary function tests, chest radiology (chest X-Ray and CT scan), sputum culture results, blood eosinophil count and cardiac investigations when available. Only spirometry studies graded either $\mathrm{A}$ to $\mathrm{B}$ or $\mathrm{C}$, as per the discretion of the respiratory physician for session quality, were included to assess severity. As there are no established predicted values for 


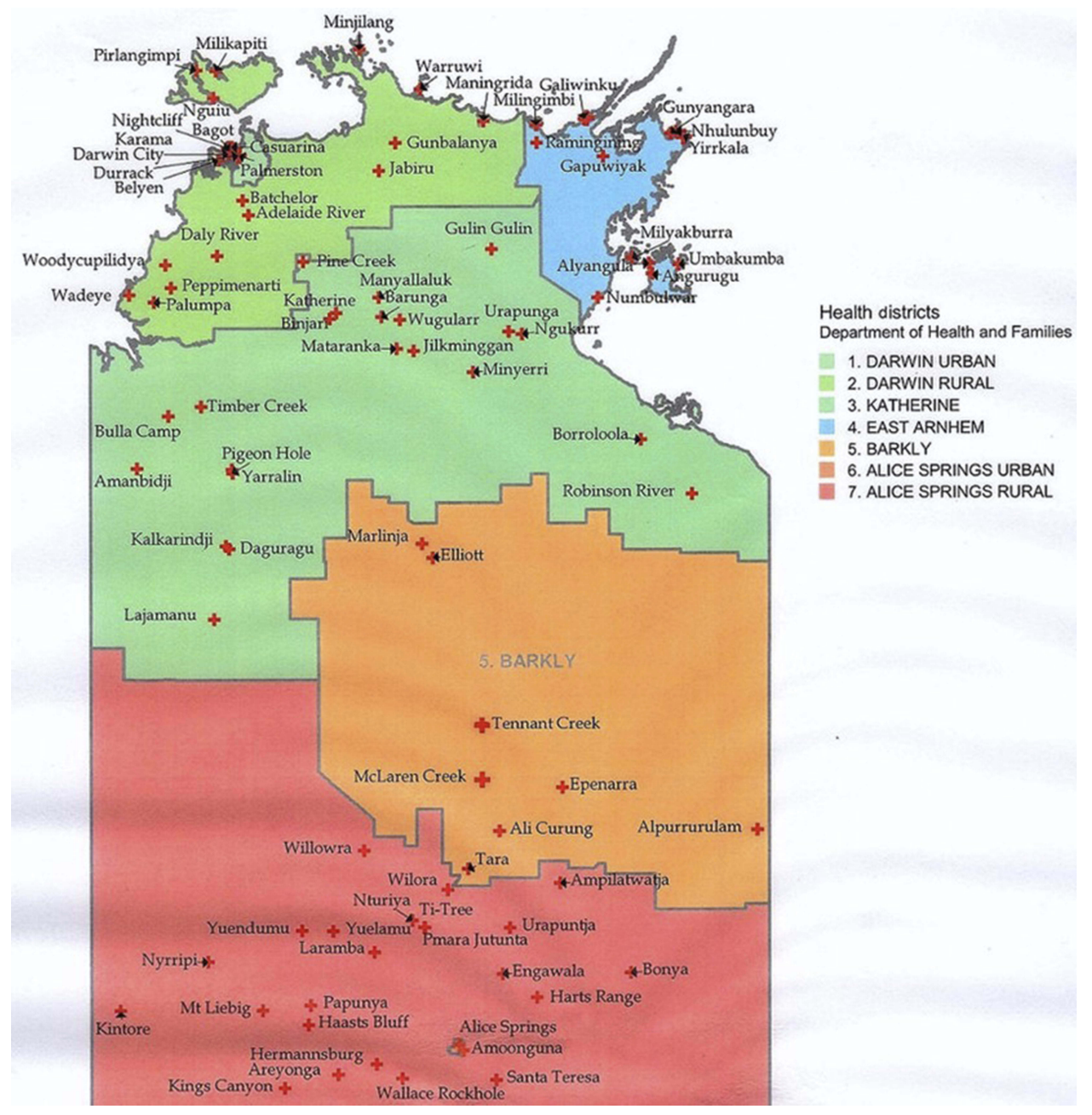

Figure I Top End Health Service map, NT, Australia.

the Indigenous population, no correctional factor for spirometry testing was used. All lung function tests were performed according to the standard published protocol and as described in a recent report from our centre. ${ }^{17}$ Hospital records were also reviewed for exacerbation of COPD, admission frequency and mortality. Exacerbations were defined as presentation to either a clinic or the hospital emergency department with acute worsening of respiratory symptoms. All individual parameters were analysed as per medical record entries, and the numbers of available information for each individual data entry are shown in the respective areas in the Results section where appropriate.

To better understand the profile of the remote Aboriginal population in northern Australia with a diagnosis of COPD, we compared the demographic and environmental data on 12 remote Aboriginal communities. Only communities with fewer than 3000 habitants, with a sample size higher than five and with more than $80 \%$ of the community being Aboriginal were included in this analysis. Data on the $1 \mathrm{~km}$ surrounding fire frequency $(250 \mathrm{~m}$ grids) in the 12 targeted remote communities from 2000 to 2016 were studied. The Australian Fire Information service provides data on fire frequency in the areas surrounding these remote communities. These data were used to calculate average fire frequency (number of fires divided by number of years) for each community and test a possible adverse respiratory outcome in the frequency of admission rates with respiratory symptoms. We used the 2016 census data for number of Aboriginal people living in these communities. The demographic values are represented as ranges instead of exact numbers to prevent community identification, as per local ethical guidelines.

\section{Statistical Considerations}

Statistical analyses were conducted using the open-source statistics programme R (R Development Core Team 2014; 
http://www.r-project.org) and Microsoft Excel 2013 (Microsoft Corporation, Redmond, WA, USA). Chisquared tests were used to find the difference in demographics and clinical variables among smoking groups (non-smokers, ex-smokers and smokers), genders and spirometry results. Kruskal-Wallis tests were used to compare the age, BMI, number of smoking pack-years, number of exacerbations and admissions per year, gender and spirometry results. Stepwise multiple regressions were used to test the effects of the target communities' average age, average BMI, percentage of smokers, past smokers/ current smokers' ratio and fire frequency on the percentage of cases with $\mathrm{FEV}_{1} / \mathrm{FVC}$ ratio $<0.7$, bronchiectasis and asthma in the communities, and the average number of exacerbations and admissions per person in the community. Owing to the large number of predictor variables and interactions, non-significant variables were excluded using stepwise elimination. Percentage values were used after arcsine transformations. For all analyses, $p<0.05$ was considered statistically significant.

\section{Ethical Considerations}

This study was approved by the Human Research Ethics Committee of the NT Department of Health/TEHS and Menzies School of Health Research (reference no: HREC 2017-2957). Consent was not obtained from the study participants, as the study was retrospective in nature and no active pharmacological or non-pharmacological interventions were investigated during the study. Furthermore, the investigators involved in this study are the usual respiratory specialist care providers for the patients included in this study and have access to patients' medical records as a part of their usual medical care. Hence, separate patients' consent to access their medical records was not required.

\section{Results}

Of the 767 patients referred to the specialist respiratory outreach clinics during the study period, 49\% $(n=380)$ had a clinical diagnosis of COPD, of whom $56 \%$ were females. The demographic characteristics, smoking status, respiratory symptoms, and other coexisting respiratory and medical comorbidities are detailed in Table 1. There was a high percentage of smokers among participants, with only $7 \%$ (26/370) identifying themselves as non-smokers, in comparison to $66.5 \%$ as current smokers (246/370) and $26.5 \%$ as former smokers (98/370). The smoking status was not
Table I Demographic Characteristics, Smoking Status, Respiratory Symptoms, And Coexisting Respiratory And Other Medical Conditions In All Patients (Available Data)

\begin{tabular}{|c|c|c|}
\hline \multicolumn{2}{|l|}{ Characteristics } & Results \\
\hline \multicolumn{2}{|l|}{ Age (years) } & $57.26 \pm 13.21 \quad(n=380)$ \\
\hline \multirow[t]{2}{*}{ Gender } & Female & $212 / 380(55.79 \%)$ \\
\hline & Male & 168/380 (44.21\%) \\
\hline \multicolumn{2}{|l|}{ Weight (kg) } & $65.81 \pm 20.37(n=282)$ \\
\hline \multicolumn{2}{|l|}{ BMI $\left(\mathrm{kg} / \mathrm{m}^{2}\right)$} & $24.30 \pm 7.01 \quad(n=272)$ \\
\hline \multirow[t]{3}{*}{ Smoking status } & Current & $246 / 370(66.49 \%)$ \\
\hline & Past & $98 / 370(26.49 \%)$ \\
\hline & Never & $26 / 370(7.03 \%)$ \\
\hline \multicolumn{2}{|l|}{ Packs per year } & $30.54 \pm 38.65(n=176)$ \\
\hline \multirow[t]{3}{*}{ Type } & Cigarettes & $340 / 367$ (92.64\%) \\
\hline & Marijuana & |4/367 (3.8I\%) \\
\hline & Rollies & I8/367 (4.90\%) \\
\hline \multirow[t]{2}{*}{ Deceased } & No & $342 / 372(91.94 \%)$ \\
\hline & Yes & $30 / 372(8.06 \%)$ \\
\hline \multirow[t]{4}{*}{ Symptoms } & $\begin{array}{l}\text { Shortness of } \\
\text { breath }\end{array}$ & 233/373 (62.47\%) \\
\hline & Productive cough & II $2 / 373(30.03 \%)$ \\
\hline & Wheeze & 100/373 (26.81\%) \\
\hline & Cough & $86 / 373(23.06 \%)$ \\
\hline \multirow[t]{5}{*}{ MRC Dyspnoea Scale } & 0 & $87 / 374(23.26 \%)$ \\
\hline & I & $118 / 374$ (31.55\%) \\
\hline & 2 & 101/374 (27.01\%) \\
\hline & 3 & $59 / 374$ (15.78\%) \\
\hline & 4 & $9 / 374(2.41 \%)$ \\
\hline \multicolumn{2}{|l|}{ Exacerbations per year } & $1.18 \pm 1.61 \quad(n=374)$ \\
\hline \multicolumn{2}{|c|}{ Hospital admissions per year } & $0.87 \pm 1.26(n=372)$ \\
\hline \multirow{7}{*}{$\begin{array}{l}\text { Other respiratory } \\
\text { conditions }\end{array}$} & Bronchiectasis & I87/374 (49.87\%) \\
\hline & Asthma & I22/374 (32.62\%) \\
\hline & Obstructive sleep & $35 / 374(9.36 \%)$ \\
\hline & $\begin{array}{l}\text { apnoea } \\
\text { Pulmonary }\end{array}$ & |4/374 (3.74\%) \\
\hline & hypertension & \\
\hline & Lung cancer & $7 / 374$ (1.87\%) \\
\hline & $\begin{array}{l}\text { Type } 2 \text { respiratory } \\
\text { failure }\end{array}$ & $3 / 374(0.80 \%)$ \\
\hline \multirow{5}{*}{$\begin{array}{l}\text { Medical } \\
\text { comorbidities }\end{array}$} & Hypertension & $68 / 372(18.28 \%)$ \\
\hline & Diabetes & $56 / 372(15.05 \%)$ \\
\hline & $\begin{array}{l}\text { Chronic renal } \\
\text { failure }\end{array}$ & $49 / 372$ (13.17\%) \\
\hline & $\begin{array}{l}\text { Coronary artery } \\
\text { disease }\end{array}$ & $40 / 372(10.75 \%)$ \\
\hline & Stroke & 9/372 (2.42\%) \\
\hline
\end{tabular}

Abbreviation: BMI, body mass index. 
available in 10 patients. In relation to age, past smokers (61.74 \pm 15.22 years old) were on average 6 years older than current smokers $(55.94 \pm 11.66$ years old $)$ and about 8 years older than non-smokers $(54.05 \pm 15.96$ years old $)$ (Table 2). During the study period 30 patients were noted to have died, representing a mortality rate of $9 \%$. Figure $2 \mathrm{~A}$ and $\mathrm{B}$ shows the yearly exacerbation rates and hospital admission frequency of the study cohort. There were 363 documented exacerbations and 366 hospital admissions in total.

The most common symptom reported was shortness of breath, in 233/373 (62.4\%). The most common coexisting respiratory condition in association with COPD was noted to be bronchiectasis $187 / 374(49.87 \%)$ in our study cohort. Coronary artery disease was documented in at least $10 \%$ of the patients. Pharmacotherapy for COPD-specific management was noted to be salbutamol as a short-acting bronchodilator (SABA) in $79 \%$, while the use of longacting muscarinic antagonists (LAMAs), long-acting beta agonists (LABAs) and inhaled corticosteroids (ICSs) was noted in $48 \%, 64 \%$ and $65 \%$, respectively. The preferred medications among LAMAs, LABAs and ICSs were tiotropium, salmeterol and fluticasone, respectively. About $10 \%$ of the patients were on long-term supplemental oxygen therapy (LTOT) (Table 1 and Figure 3).

Spirometry data, radiology, sputum culture and echocardiogram results are shown in Table 3. Out of 280 spirometry results available from the medical records, 175 were considered suitable for analysis. Of these, $78.8 \%$ had an $\mathrm{FEV}_{1} / \mathrm{FVC}$ ratio $<0.70(0.56 \pm 0.17)$. The mean $\mathrm{FEV}_{1}$ was noted to be $42 \%$ of predicted value, indicating moderate to severe airflow obstruction, and a bronchodilator response was noted in $28.6 \%$ (41/143) of patients. Post-bronchodilator $\mathrm{FEV}_{1} / \mathrm{FVC}$ ratios were documented in 156 patients, which showed a ratio of 0.57 \pm 0.17 . Chest X-ray/CT scan results were available in 227 and 139 patients, respectively, which showed COPD changes and the presence of coexisting bronchiectasis in a significant number of patients, and Pseudomonas aeruginosa was the predominant organism cultured in the sputum.

A gender comparison among the study cohort is shown in Table 4. We found significant gender differences in smoking and cardiac dysfunction. The gender difference in BMI was close to significance $(p=0.05)$. Females $(25.0$ $\left.\pm 7.3 \mathrm{~kg} / \mathrm{m}^{2}\right)$, on average, had a BMI $1.7 \mathrm{~kg} / \mathrm{m}^{2}$ higher than males $\left(23.3 \pm 6.4 \mathrm{~kg} / \mathrm{m}^{2}\right)$. Males $(39.5 \pm 51.8$ packs $)$ smoked on average 16 more packs of cigarettes per year than females (23.4 \pm 21.4 packs). Furthermore, a higher number of males were diagnosed with cardiac failure in comparison to females, although the numbers were small. There were no gender differences in COPD symptoms or hospital admission frequencies.

Table 5 shows the relationships in smoking status, comparison between genders, symptoms and BMI among patients with $\mathrm{FEV}_{1} / \mathrm{FVC}<0.7$ and $\mathrm{FEV}_{1} / \mathrm{FVC}$ $\geq 0.7$. We found significant differences in regard to spirometry results for gender, BMI and co-occurrence with bronchiectasis among patients with an $\mathrm{FEV}_{1} / \mathrm{FVC}$ ratio $<0.7$. We noticed that more females had an $\mathrm{FEV}_{1} / \mathrm{FVC}$ ratio $<0.7$ compared to males $(54.3 \%$ vs $45.7 \%)$ and we also observed that patients with $\mathrm{FEV}_{1} / \mathrm{FVC}<0.7$ had an average BMI $5.1 \mathrm{~kg} / \mathrm{m}^{2}$ lower $\left(23.4 \pm 6.3 \mathrm{~kg} / \mathrm{m}^{2}\right)$ than patients with $\quad \mathrm{FEV}_{1} / \mathrm{FVC} \geq 0.7 \quad\left(28.5 \pm 8.7 \quad \mathrm{~kg} / \mathrm{m}^{2}\right)$. Furthermore, patients with $\mathrm{FEV}_{1} / \mathrm{FVC}<0.7$ had a $20 \%$ higher incidence of bronchiectasis than those with $\mathrm{FEV}_{1}$ / FVC $\geq 0.7$ (55.1\% vs $35.1 \%$ ). Cardiac dysfunction and type 2 respiratory failure were also observed in patients with $\mathrm{FEV}_{1} / \mathrm{FVC}$ ratio $<0.7$; however, the numbers were not significant.

Table 2 Relationship Between Smoking Status (Current, Past And Never Smoking History) And Age, BMI, Exacerbations And Hospital Admissions

\begin{tabular}{|l|l|l|l|l|l|}
\hline \multirow{2}{*}{ Results } & Overall & \multicolumn{2}{|l|}{ Smoking Status } & \multirow{2}{*}{} \\
\cline { 3 - 6 } & & Current & Past & Never \\
\hline Total & 370 & 66.5 & 26.5 & 7.0 & $p<0.05$ \\
Age (years) & $57.25 \pm 13.21$ & $55.94 \pm 11.66$ & $61.74 \pm 15.22$ & $54.05 \pm 15.96$ & $p<0.05$ \\
BMI $\left(\mathrm{kg} / \mathrm{m}^{2}\right)$ & $24.30 \pm 7.01$ & $24.15 \pm 7.46$ & $24.41 \pm 6.13$ & $25.53 \pm 6.56$ & $p=0.47$ \\
Exacerbations per year & $1.18 \pm 1.61$ & $1.12 \pm 1.38$ & $1.29 \pm 2.07$ & $1.38 \pm 1.92$ & $p=0.97$ \\
Admissions per year & $0.87 \pm 1.26$ & $0.86 \pm 1.17$ & $0.93 \pm 1.53$ & $0.85 \pm 1.19$ & $p=0.98$ \\
\hline
\end{tabular}

Note: Bold text indicates significance.

Abbreviation: BMI, body mass index. 


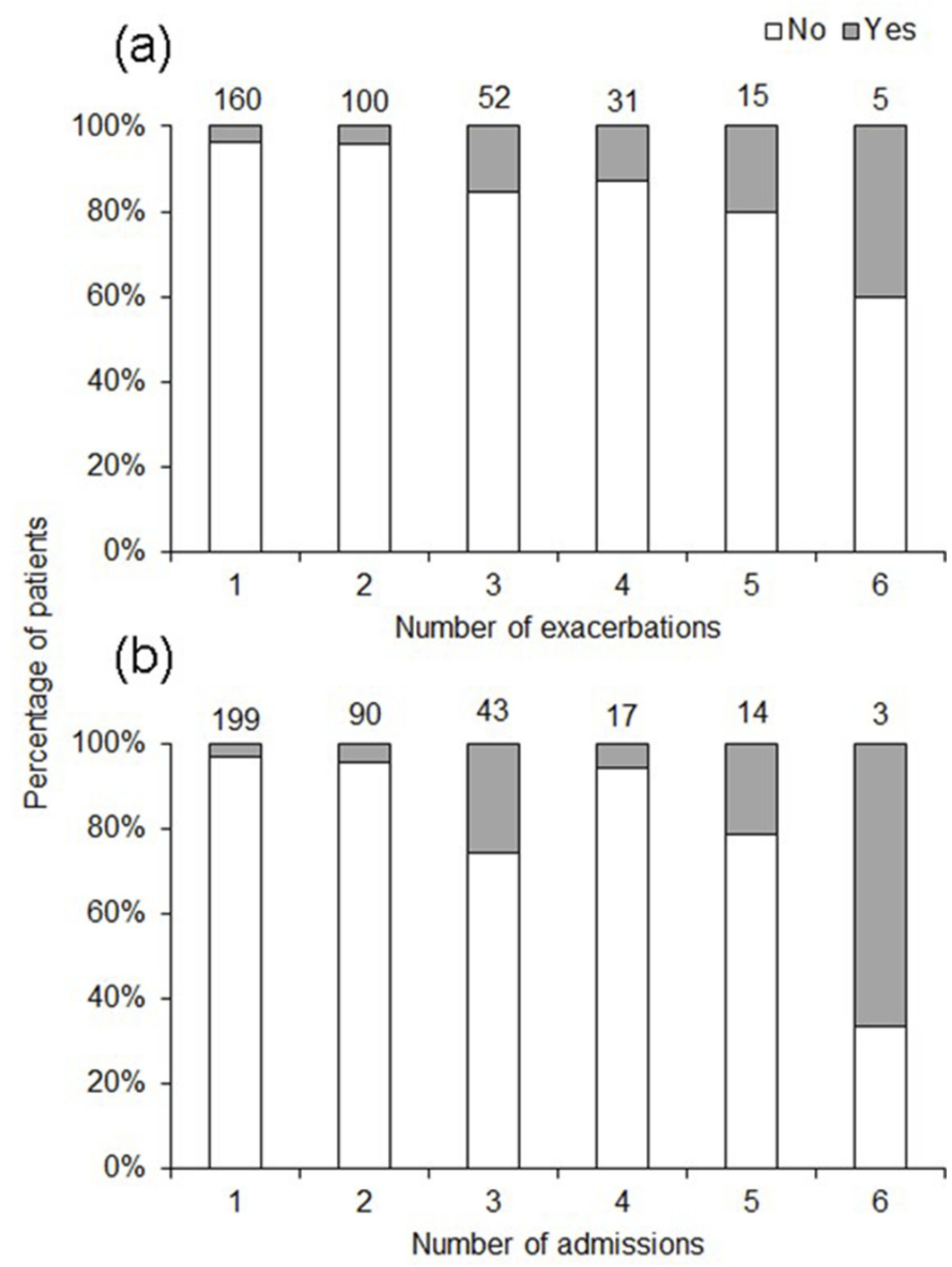

Figure 2 Percentage of deceased (yes, grey bars) and non-deceased (no, white bars) participants in relation to (A) number of exacerbations and (B) number of admissions. The three participants with over six exacerbations and the four participants with over six admissions were excluded from the figure. Numbers on the top of the bars represent number of participants with a given number of exacerbation/admissions.

The community and fire frequency data showed that the average age in the 12 small Aboriginal target communities was between 49 and 61 years (Table 6). The average BMI ranged from 19 to $29 \mathrm{Kg} / \mathrm{m}^{2}$, with only four communities of the study participants had a BMI over 25 $\mathrm{Kg} / \mathrm{m}^{2}$. The community fire frequency ranged from 1.0 to 8.3 (average number of fires over the past 17 years). Although we analysed communities with similar demographics, we observed a high variation in the levels of COPD among communities. The percentage of individuals in the communities ranged from $0.1 \%$ to $1.8 \%$ with an $\mathrm{FEV}_{1} / \mathrm{FVC}$ ratio $<0.7$, from $0.1 \%$ to $2.4 \%$ with asthma and from $0.2 \%$ to $2.4 \%$ with bronchiectasis. Community average exacerbations per participant ranged from 0.5 to 1.7 and the rate of hospital admissions ranged from $0.4 \%$ to $1.1 \%$.

Stepwise multiple regressions were used to test the relationships between COPD in the 12 small Aboriginal communities and demography (Tables 6 and 7). Communities with a higher proportion of smokers had a higher percentage of participants with an $\mathrm{FEV}_{1} / \mathrm{FVC}$ ratio $<0.7$ (Table 7). Communities with a higher proportion of participants with asthma had a higher proportion of smokers and on average were younger (Table 7). Communities with a higher fire frequency history in their surroundings had a lower average number of exacerbations per patient (Table 7). The number of exacerbations ranged from 0 to 16 , with only three participants having more than six 


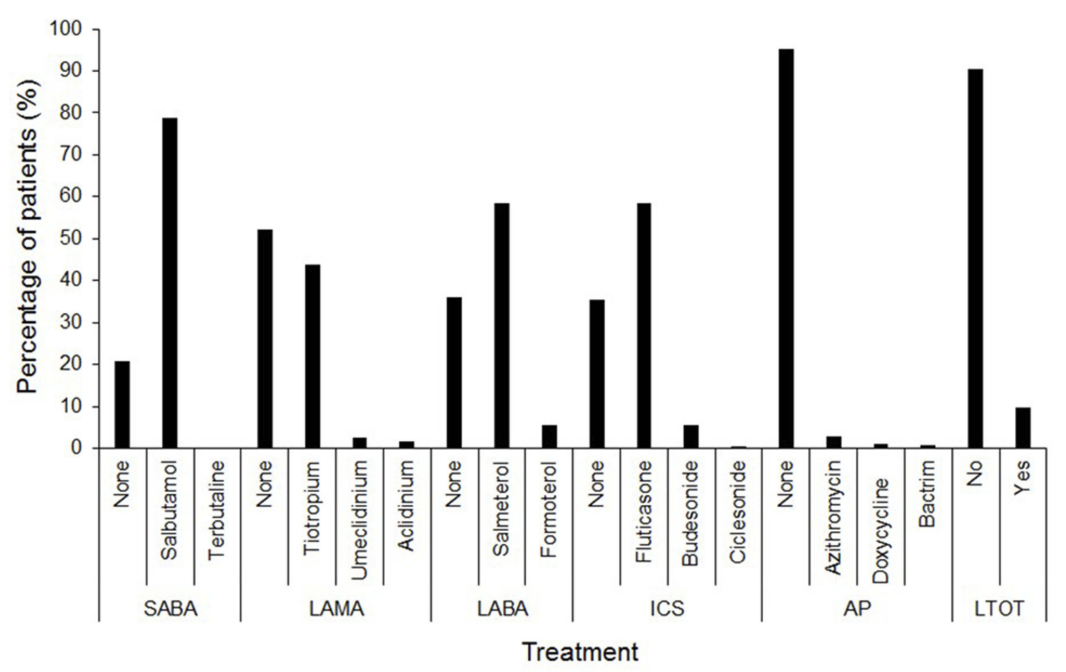

Figure 3 Treatment details for all patients (available data): short-acting beta-agonists (SABA, $n=374$ ), long-acting muscarinic antagonists (LAMA, $n=373$ ), long-acting betaagonists (LABA, $n=373$ ), inhaled corticosteroids (ICS, $n=372)$, antibiotic prophylaxis $(A P, n=374)$ and long-term oxygen therapy $(L T O T, n=375)$.

exacerbations. Mortality increased with number of exacerbations (Figure 2A and B) and participants who had died by the end of the study had had a higher number of exacerbations in comparison to participants who were still alive (Mann-Whitney $U$-test: $W=2854, \quad p<0.05$ ). Although only close to significance, communities with a higher average number of hospital admissions per patient were, on average, older $(p=0.07)$. The number of admissions ranged from 0 to 10 during the study period, with only four participants having more than six admissions.

\section{Discussion}

This is one of the first studies documenting the COPD clinical profile and disease burden in Aboriginal patients living in the remote and regional communities of the Top End of the Northern Territory in Australia. This study confirms that smoking rates are very high in Aboriginal people, which is the main risk factor for the development of COPD. Moreover, our study shows that this population has moderate to severe airflow obstruction and a high symptom burden. The most common coexisting respiratory condition associated with COPD was bronchiectasis, and worsening airflow obstruction was associated with a diagnosis of bronchiectasis when the two conditions coexisted. Furthermore, mortality was higher in patients with frequent exacerbations and hospital admissions.

Our study adds to the limited pool of knowledge, as noted in the Canadian Indigenous study, showing that COPD is strongly associated with Aboriginal status, age, smoking, low socioeconomic status and limited access to healthcare systems. ${ }^{18,19}$ Systematic reviews have shown that Indigenous people from other parts of the world have an increased prevalence of respiratory pathology, in particular obstructive airway disease, compared to nonIndigenous people. ${ }^{20,21}$

A higher medical comorbid burden is noted among Indigenous people living in remote communities of Australia, with rates higher than national health survey figures. In Indigenous people aged 50 years and over, prevalence rates for hypertension and renal disease are above $50 \%$, diabetes $40 \%$, COPD $30 \%$ and coronary artery disease above $20 \%{ }^{22,23}$ Our study further supports this finding as up to $50 \%$ of the patients who were referred to the respiratory specialist service had a diagnosis of COPD. The presence of COPD with other chronic comorbid conditions may give rise to long-term adverse health consequences. We noticed that a high number of patients had exacerbations during this study period. It is reasonable to assume that the economic cost of managing the exacerbation and hospital admissions can be substantial, especially when taking patients to a major tertiary hospital from remote and regional communities. We noted higher admission and exacerbation rates in patients with lower $\mathrm{FEV}_{1} /$ FVC ratios. A previous study from our centre on spirometry data in Indigenous Australian patients showed relatively poor lung function, particularly reduced $\mathrm{FEV}_{1}$ (55\% of predicted) and FVC (61\% of predicted), but with a preserved $\mathrm{FEV}_{1} / \mathrm{FVC}$ ratio. ${ }^{17}$ This current study further confirms poor lung function in Aboriginal patients with COPD. 
Table 3 Spirometry Values, Sputum Culture, Eosinophil Count, Radiology And Echocardiogram Results In All Patients (Available Data)

\begin{tabular}{|c|c|c|}
\hline Investigations & Parameters & Results \\
\hline Spirometry results & $\begin{array}{l}\mathrm{FEV}_{\mathrm{I}}(\mathrm{L}) \\
\mathrm{FEV},(\%) \\
\mathrm{FVC}(\mathrm{L}) \\
\mathrm{FVC}(\%) \\
\mathrm{FEV}_{1} / \mathrm{FVC}<0.7 \\
\mathrm{FEV}_{\mathrm{I}} / \mathrm{FVC} \text { ratio } \\
\text { (mean) } \\
\text { Post- } \\
\text { bronchodilator } \\
\text { values } \\
\mathrm{FEV} / \mathrm{FVC} \text { (mean) } \\
\mathrm{TLC}(\%) \\
\mathrm{DLCO}(\%)\end{array}$ & $\begin{array}{l}1.26 \pm 0.59(n=175) \\
42.30 \pm 18.24 \quad(n=175) \\
2.13 \pm 0.72 \quad(n=175) \\
56.35 \pm 17.22 \quad(n=175) \\
138 / 175(78.86 \%) \\
0.56 \pm 0.17(n=175) \\
\\
0.57 \pm 0.17(n=156) \\
77.54 \pm 26.10 \quad(n=39) \\
59.33 \pm 35.00 \quad(n=38)\end{array}$ \\
\hline $\begin{array}{l}\text { Bronchodilator } \\
\text { response }\end{array}$ & $\begin{array}{l}\text { No } \\
\text { Yes }\end{array}$ & $\begin{array}{l}102 / 143(71.33 \%) \\
41 / 143(28.67 \%)\end{array}$ \\
\hline Chest $X$-ray findings & $\begin{array}{l}\text { COPD and } \\
\text { hyperinflated } \\
\text { Normal } \\
\text { COPD and } \\
\text { bronchiectasis } \\
\text { Predominant } \\
\text { bronchiectasis } \\
\text { COPD and } \\
\text { cardiomegaly } \\
\text { COPD and } \\
\text { pulmonary infiltrates } \\
\text { Nodules } \\
\text { COPD and } \\
\text { interstitial opacity }\end{array}$ & $\begin{array}{l}72 / 227(31.58 \%) \\
58 / 227(25.44 \%) \\
49 / 227(21.49 \%) \\
26 / 227(11.40 \%) \\
9 / 227(3.95 \%) \\
5 / 227(2.19 \%) \\
4 / 227(1.75 \%) \\
4 / 227(1.75 \%)\end{array}$ \\
\hline $\begin{array}{l}\text { Chest CT scan } \\
\text { findings }\end{array}$ & $\begin{array}{l}\text { Bronchiectasis and } \\
\text { emphysema } \\
\text { Predominant } \\
\text { emphysema } \\
\text { Emphysema and } \\
\text { fibrosis } \\
\text { Lung nodules } \\
\text { Normal }\end{array}$ & $\begin{array}{l}53 / 139(38.12 \%) \\
41 / 139(29.50 \%) \\
18 / 139(12.95 \%) \\
17 / 139(12.23 \%) \\
10 / 139(7.19 \%)\end{array}$ \\
\hline $\begin{array}{l}\text { Cardiac } \\
\text { echocardiogram } \\
\text { findings }\end{array}$ & $\begin{array}{l}\text { Normal } \\
\text { Valvular anomalies } \\
\text { Pulmonary } \\
\text { hypertension } \\
\text { Left ventricle systolic } \\
\text { dysfunction } \\
\text { Right ventricle } \\
\text { dysfunction }\end{array}$ & $\begin{array}{l}35 / 93(37.63 \%) \\
26 / 93(27.96 \%) \\
13 / 93(13.98 \%) \\
11 / 93(11.83 \%) \\
8 / 93(8.60 \%)\end{array}$ \\
\hline Blood count & Eosinophil count & $0.29 \pm 0.34(n=187)$ \\
\hline
\end{tabular}

(Continued)
Table 3 (Continued).

\begin{tabular}{|l|l|l|}
\hline Investigations & Parameters & Results \\
\hline Sputum culture & Oropharyngeal flora & $66 / 160(41.25 \%)$ \\
results & Pseudomonas & $21 / 160(13.13 \%)$ \\
& Streptococcus & $5 / 160(3.13 \%)$ \\
& pneumoniae & \\
& Aspergillus & $4 / 160(2.50 \%)$ \\
& Haemophilus & $7 / 160(2.38 \%)$ \\
& influenzae & \\
& Staphylococcus aureus & $3 / 160(1.88 \%)$ \\
& NTM & $2 / 160(1.25 \%)$ \\
& Pseudomonas and H. & $2 / 160(1.25 \%)$ \\
& influenzae & \\
& Pseudomonas and & $1 / 160(0.63 \%)$ \\
& NTM & $1 / 160(0.63 \%)$ \\
& Pseudomonas and & \\
& Staphylococcus & $1 / 160(0.63 \%)$ \\
& S. pneumoniae and $H$. & \\
& influenzae & $24 / 160(15.00 \%)$ \\
& Nil & $23 / 160(14.38 \%)$ \\
\hline & Other &
\end{tabular}

Abbreviations: $\mathrm{FEV}_{1}$, forced expiratory volume in one second; $\mathrm{FVC}$, forced vital capacity; TLC, total lung capacity; DLCO, diffusing capacity of the lungs for carbon monoxide; COPD, chronic obstructive pulmonary disease; NTM, non-tuberculous mycobacterium.

In our study a high proportion of patients had underlying bronchiectasis along with COPD. It is well established that the presence of bronchiectasis along with COPD is an independent risk factor for all-cause mortality. ${ }^{24}$ Furthermore, the presence of bronchiectasis can contribute to further reduction in lung function and increased hospital admissions due to exacerbations. ${ }^{25} \mathrm{We}$ also noted a similar trend in our study patients, which showed communities with a higher proportion of smokers to have a higher percentage of patients with $\mathrm{FEV}_{1} / \mathrm{FVC}$ ratio $<0.7$ and bronchiectasis. Further research is warranted to study the health implications and management strategies of adult Aboriginal patients diagnosed with a combination of COPD and bronchiectasis. This may also represent a different COPD phenotype in Aboriginal patients.

In this study the most common pathogen isolated from sputum was Pseudomonas. The use of inhaled corticosteroids has been linked to higher lower respiratory tract infection rates. ${ }^{26}$ In our study about $58 \%$ of the patients were on inhaled fluticasone. It is beyond the scope of this study to determine whether high-dose inhaled steroids increased the rates of infection and exacerbations in this 
Table 4 Demographic Data, Smoking Status, Symptoms, Exacerbations, Admission Frequency And Investigations Performed, According To Gender (Female and Male)

\begin{tabular}{|c|c|c|c|c|c|}
\hline Results & & Overall & Female & Male & Statistics \\
\hline \multicolumn{2}{|l|}{ Gender } & $380(100 \%)$ & $212(55.8 \%)$ & $168(44.2 \%)$ & $p<0.05$ \\
\hline \multicolumn{2}{|l|}{ Age (years) } & $57.3 \pm 13.2$ & $56.9 \pm 12.6$ & $57.7 \pm 14.0$ & $p=0.52$ \\
\hline \multicolumn{2}{|l|}{ BMI $\left(\mathrm{kg} / \mathrm{m}^{2}\right) \quad(\mathrm{n}=27 \mathrm{I})$} & $24.3 \pm 7.0$ & $25.0 \pm 7.3$ & $23.3 \pm 6.4$ & $p \leq 0.05$ \\
\hline Smoking status $(n=370)$ & $\begin{array}{l}\text { Current } \\
\text { Past } \\
\text { Never }\end{array}$ & $\begin{array}{l}66.50 \% \\
26.50 \% \\
7 \%\end{array}$ & $\begin{array}{l}66.30 \% \\
25.50 \% \\
8.20 \%\end{array}$ & $\begin{array}{l}66.70 \% \\
27.80 \% \\
5.60 \%\end{array}$ & $p=0.59$ \\
\hline \multicolumn{2}{|l|}{ Packs per year $(n=156)$} & $30.5 \pm 38.7$ & $23.4 \pm 21.4$ & $39.5 \pm 51.8$ & $p<0.05$ \\
\hline Symptoms $(n=373)$ & $\begin{array}{l}\text { SOB } \\
\text { Productive cough } \\
\text { Wheeze } \\
\text { Cough }\end{array}$ & $\begin{array}{l}62.50 \% \\
30 \% \\
26.80 \% \\
23.10 \%\end{array}$ & $\begin{array}{l}65.70 \% \\
30 \% \\
25.20 \% \\
20.50 \%\end{array}$ & $\begin{array}{l}58.30 \% \\
30.10 \% \\
28.80 \% \\
26.40 \%\end{array}$ & $\begin{array}{l}p=0.14 \\
p=1.00 \\
p=0.44 \\
p=0.18\end{array}$ \\
\hline \multicolumn{2}{|c|}{ Exacerbations per year $(n=374)$} & $1.2 \pm 1.6$ & $1.2 \pm 1.4$ & $1.2 \pm 1.9$ & $p=0.42$ \\
\hline \multicolumn{2}{|c|}{ Admissions per year $(n=372)$} & $0.9 \pm 1.3$ & $0.8 \pm 1.1$ & $0.9 \pm 1.4$ & $p=0.85$ \\
\hline Echocardiogram $(n=93)$ & $\begin{array}{l}\text { Valvular anomalies } \\
\text { PHT } \\
\text { LV dysfunction } \\
\text { RHF } \\
\text { Normal }\end{array}$ & $\begin{array}{l}28 \% \\
14 \% \\
11.80 \% \\
8.60 \% \\
37.60 \%\end{array}$ & $\begin{array}{l}28.30 \% \\
10.90 \% \\
4.30 \% \\
10.90 \% \\
45.70 \%\end{array}$ & $\begin{array}{l}27.70 \% \\
17 \% \\
19.10 \% \\
6.40 \% \\
29.80 \%\end{array}$ & $\begin{array}{l}p=0.95 \\
p=0.39 \\
p<0.05 \\
p=0.44 \\
p=0.11\end{array}$ \\
\hline
\end{tabular}

Note: Bold text indicates significance.

Abbreviations: BMI, body mass index; SOB, shortness of breath; PHT, pulmonary hypertension; LV dysfunction, left ventricle dysfunction; RHF, right heart failure.

study population, especially in the presence of underlying bronchiectasis.

Asthma-COPD overlap syndrome is being increasingly recognised as a disease with a different phenotype and a worse quality of life. ${ }^{27,28}$ We noticed that about $34 \%$ of the patients also had a documented diagnosis of asthma along with smoking-related COPD. Spirometry data showed the presence of a bronchodilator response in $28.6 \%$. It is not entirely clear whether this represents asthma-COPD overlap syndrome in this study cohort and this may require further dedicated research for appropriate diagnosis and management strategies.

Cardiovascular morbidity and mortality drastically increase in the presence of COPD. ${ }^{29}$ We found that only 93/380 patients $(24 \%)$ had undergone cardiac investigations during this study period, in particular echocardiogram, and about $19 \%$ had cardiac dysfunction. It is likely that several patients may have underlying cardiac dysfunction and have not been diagnosed and appropriately managed. Robust efforts to actively investigate and treat cardiac dysfunction in Aboriginal patients with COPD may be needed.
People living in the regional and remote communities in the study area are constantly exposed to environmental smoke due to local vegetation fires, during which they are exposed to poor air quality, which can give rise to respiratory symptoms. ${ }^{30-32}$ In this study we made an attempt to explore the fire frequency in the remote and regional areas and the numbers of exacerbations and hospital admissions. Given the previous literature on the effects of ambient biomass smoke on cardiorespiratory health, our results were unexpected. Communities with higher average fire frequency had significantly fewer average exacerbations per year. More studies are needed to better understand this relationship, which could be direct or indirect. For example, this result could be an indication of the positive influence of traditional burning on the community surroundings. ${ }^{33,34}$ Areas with more frequent fires have lower vegetation biomass (fuel load), which may translate into less intense fires and consequently better air quality during fires and less negative effects on respiratory symptom exacerbations. Another indirect effect could be related to the better physical and mental health of Aboriginal people actively working in the management of their land. ${ }^{35,36}$ 
Table 5 Demographic Data, Comorbidities And Investigations Performed, According To Spirometry Results

\begin{tabular}{|c|c|c|c|c|c|}
\hline Results & & Overall & FEV / FVC $\geq 0.7$ & FEV / $/$ FVC $<0.7$ & Statistics \\
\hline Total & & 175 & $37(21.1 \%)$ & I 38 (78.9\%) & $p<0.05$ \\
\hline Gender & $\begin{array}{l}\text { Female } \\
\text { Male }\end{array}$ & $\begin{array}{l}103(58.9 \%) \\
72(41.1 \%)\end{array}$ & $\begin{array}{l}28(75.7 \%) \\
9(24.3 \%)\end{array}$ & $\begin{array}{l}75(54.3 \%) \\
63(45.7 \%)\end{array}$ & $\boldsymbol{p}<0.05$ \\
\hline Age (years) $(n=174)$ & & $56.5 \pm 11.5$ & $56.1 \pm 10.8$ & $56.8 \pm 11.7$ & $p=0.81$ \\
\hline BMI $\left(\mathrm{kg} / \mathrm{m}^{2}\right)(\mathrm{n}=|7|)$ & & $25.9 \pm 7.1$ & $28.5 \pm 8.7$ & $23.4 \pm 6.3$ & $\mathbf{p}<0.05$ \\
\hline Smoking status $(n=173)$ & $\begin{array}{l}\text { Current } \\
\text { Past } \\
\text { Never }\end{array}$ & $\begin{array}{l}59 \% \\
34.10 \% \\
6.90 \%\end{array}$ & $\begin{array}{l}67.60 \% \\
24.30 \% \\
8.10 \%\end{array}$ & $\begin{array}{l}56.60 \% \\
36.80 \% \\
6.60 \%\end{array}$ & $p=0.37$ \\
\hline Packs per year $(n=80)$ & & $27.7 \pm 24.0$ & $30.6 \pm 26.1$ & $24.7 \pm 17.2$ & $p=0.55$ \\
\hline Comorbidity $(n=172)$ & $\begin{array}{l}\text { HTN } \\
\text { DM } \\
\text { CRF } \\
\text { CAD } \\
\text { Stroke } \\
\text { Other }\end{array}$ & $\begin{array}{l}14.50 \% \\
11.60 \% \\
9.90 \% \\
7.60 \% \\
1.20 \% \\
49.40 \%\end{array}$ & $\begin{array}{l}11.10 \% \\
8.30 \% \\
11.10 \% \\
5.60 \% \\
2.80 \% \\
52.80 \%\end{array}$ & $\begin{array}{l}15.40 \% \\
12.50 \% \\
9.60 \% \\
8.10 \% \\
0.70 \% \\
48.50 \%\end{array}$ & $\begin{array}{l}p=0.51 \\
p=0.49 \\
p=0.78 \\
p=0.61 \\
p=0.31 \\
p=0.65\end{array}$ \\
\hline Other respiratory conditions $(n=175)$ & $\begin{array}{l}\text { Bronchiectasis } \\
\text { Asthma } \\
\text { OSA } \\
\text { PHT } \\
\text { Lung cancer } \\
\text { ChT2RF }\end{array}$ & $\begin{array}{l}49.90 \% \\
36.60 \% \\
10.30 \% \\
4 \% \\
2.30 \% \\
1.10 \%\end{array}$ & $\begin{array}{l}35.10 \% \\
45.90 \% \\
5.40 \% \\
2.70 \% \\
2.70 \% \\
0 \%\end{array}$ & $\begin{array}{l}55.10 \% \\
34.10 \% \\
11.60 \% \\
4.30 \% \\
2.20 \% \\
1.40 \%\end{array}$ & $\begin{array}{l}p<0.05 \\
p=0.18 \\
p=0.27 \\
p=0.65 \\
p=0.85 \\
p=0.46\end{array}$ \\
\hline Echocardiogram $(n=46)$ & $\begin{array}{l}\text { Valvular anomalies } \\
\text { PHT } \\
\text { RHF } \\
\text { LV failure } \\
\text { Normal }\end{array}$ & $\begin{array}{l}26.10 \% \\
10.90 \% \\
10.90 \% \\
8.70 \% \\
43.50 \%\end{array}$ & $\begin{array}{l}6.50 \% \\
2.20 \% \\
2.20 \% \\
0 \% \\
8.70 \%\end{array}$ & $\begin{array}{l}19.60 \% \\
8.70 \% \\
8.70 \% \\
8.70 \% \\
34.80 \%\end{array}$ & $\begin{array}{l}p=0.58 \\
p=0.98 \\
p=0.98 \\
p=0.30 \\
p=0.95\end{array}$ \\
\hline
\end{tabular}

Note: Bold text indicates significance.

Abbreviations: BMI, body mass index; HTN, hypertension; DM, diabetes mellitus; CRF, chronic renal failure; CAD, coronary artery disease; OSA, obstructive sleep apnoea; PHT, pulmonary hypertension; ChT2RF, chronic type 2 respiratory failure; RHF, right heart failure; LV failure, left ventricular failure.

Although our study describes the clinical profile and disease burden of Australian Aboriginal patients with a diagnosis of COPD, this study also supports the need for further research and for policy makers and the healthcare system to implement appropriate intervention strategies to reduce the high respiratory disease burden in this population. Further efforts and collaboration with clinicians and allied healthcare workers, along with community engagement programmes, ${ }^{37,38}$ are needed to address preventive and appropriate management strategies to reduce the COPD disease burden, morbidity, mortality and economic cost in Aboriginal people suffering from COPD, not only in Australia but also in the other parts of the world, and may require further dedicated efforts among organisations caring for such patients.

\section{Limitations Of The Study}

The results of this study should be viewed with caution, as the study participants included were those referred to specialist respiratory services and the results do not represent the entire remote and regional Aboriginal population of Australia. As this was a retrospective study, only available data were included in the analysis; this could have led to the outcome being under- or overestimated, which is a well-recognised issue inherent to retrospective study design. However, this may also indicate that people living in remote communities may not have access to appropriate investigations. Nevertheless, despite some limitations, this is the first study demonstrating the clinical profile and morbidity/mortality from COPD in Aboriginal patients living in regional and remote parts of the Northern Territory of Australia. 

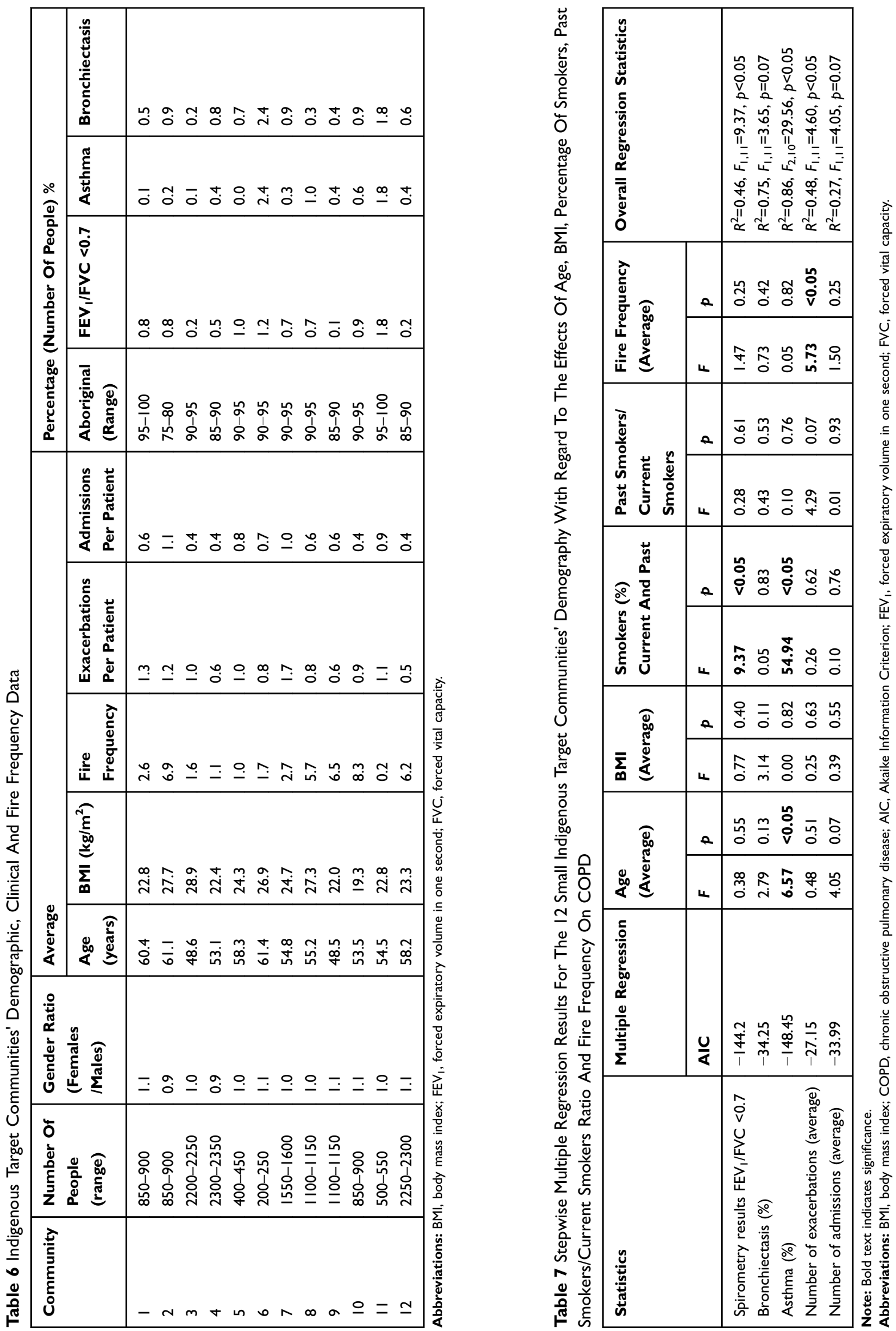


\section{Conclusion}

Australian Aboriginal patients living in regional and remote communities of the Northern Territory had higher smoking rates, moderate to severe airflow obstruction on spirometry and bronchiectasis as the most common associated respiratory condition coexisting along with COPD. Patients with bronchiectasis and COPD had lower $\mathrm{FEV}_{1} /$ FVC ratios, and asthma was more often co-diagnosed in younger smokers. Mortality increased with increasing number of exacerbations and hospital admissions. Furthermore, our study demonstrates the need for further research and the implementation of appropriate intervention strategies to reduce the high burden of respiratory disease burden in this population.

\section{Disclosure}

All authors declare no conflicts of interest in this work.

\section{References}

1. Burney PG, Patel J, Newson R, Minelli C, Naghavi M. Global and regional trends in COPD mortality, 1990-2010. Eur Respir J. 2015;45:1239-1247. doi:10.1183/09031936.00142414

2. Lozano R, Naghavi M, Foreman K, et al. Global and regional mortality from 235 causes of death for 20 age groups in 1990 and 2010: a systematic analysis for the global burden of disease study 2010 . Lancet. 2012;380:2095-2128. doi:10.1016/S0140-6736(12)61728-0

3. Pesce G. Mortality rates for chronic lower respiratory diseases in Italy from 1979 to 2010: an age-period-cohort analysis. ERJ Open Res. 2016;2:00093-2015. doi:10.1183/23120541.00093-2015

4. Viegi G, Scognamiglio A, Baldacci S, Pistelli F, Carrozzi L. Epidemiology of chronic obstructive pulmonary disease (COPD). Respiration. 2001;68:4-19. doi:10.1159/000050456

5. Australian Institute of Health and Welfare 2010. Asthma, chronic obstructive pulmonary disease and other respiratory diseases in Australia. Cat. no. ACM 20. Canberra: AIHW.

6. Thomas DP, Condon JR, Anderson IP, et al. Long-term trends in indigenous deaths from chronic diseases in the Northern territory: a foot on the brake, a foot on the accelerator. Med $J$ Aust. 2006;185:145-149.

7. Vos T, Barker B, Begg S, Stanley L, Lopez AD. Burden of disease and injury in aboriginal and Torres Strait Islander peoples: the indigenous health gap. Int J Epidemiol. 2009;38:470-477. doi:10.1093/ ije/dyn240

8. Andreasyan K, Hoy WE. Patterns of mortality in indigenous adults in the Northern Territory, 1998-2003: are people living in more remote areas worse off? Med J Aust. 2009;190:307-311.

9. Toelle BG, Xuan W, Bird TE, et al. Respiratory symptoms and illness in older Australians: the Burden of Obstructive Lung Disease (BOLD) study. Med J Aust. 2013;198:144-148. doi:10.5694/ mja11.11640

10. Australian Centre for Asthma Monitoring; Marks G, Reddel H, Cooper S, Poulos L, Ampon R, Waters A. Asthma in Australia 2011: With a Focus Chapter on Chronic Obstructive Pulmonary Disease. Canberra: AIHW; 2011. Available from: www.aihw.gov.au.

11. Johnston V, Thomas DP. Smoking behaviours in a remote Australian indigenous community: the influence of family and other factors. Soc Sci Med. 2008;67:1708. doi:10.1016/j.socscimed.2008.09.016
12. Kruavit A, Fox M, Pearson R, Heraganahally S. Chronic respiratory disease in the regional and remote population of the northern territory top end: a perspective from the specialist respiratory outreach service. Aust J Rural Health. 2017;25:275-284. doi:10.1111/ajr.2017.25. issue-5

13. Penman TD, Christie FJ, Andersen AN, et al. Prescribed burning: how can it work to conserve the things we value? Int $J$ Wildland Fire. 2011;20:721-733. doi:10.1071/WF09131

14. Bowman DM, Johnston FH. Wildfire smoke, fire management, and human health. Eco Health. 2005;2:76-80.

15. Johnston FH, Bailie RS, Pilotto LS, Hanigan IC. Ambient biomass smoke and cardio-respiratory hospital admissions in Darwin, Australia. BMC Public Health. 2007;7:240. doi:10.1186/1471-24587-240

16. Reisen F, Meyer CM, McCaw L, et al. Impact of smoke from biomass burning on air quality in rural communities in southern Australia. Atmos Environ. 2011;45:3944-3953. doi:10.1016/j. atmosenv.2011.04.060

17. Schubert J, Kruavit A, Mehra S, Wasgewatta S, Chang AB, Heraganahally S. Prevalence and nature of lung function abnormalities among indigenous Australians referred to specialist respiratory outreach clinics in the Northern Territory. Intern Med J 2018. doi:10.1111/imj. 14112

18. Bird Y, Moraros J, Mahmood R, Esmaeelzadeh S, Soe NMK. Prevalence and associated factors of COPD among aboriginal peoples in Canada: a cross-sectional study. Int J Chron Obstruct Pulmon Dis. 2017;12:1915-1922. doi:10.2147/COPD.S150887

19. Ospina MB, Voaklander DC, Senthilselvan A, et al. Incidence and prevalence of chronic obstructive pulmonary disease among aboriginal peoples in Alberta, Canada. PLoS One. 2015;10:e123204. doi:10.1371/journal.pone.0123204

20. Basnayake T, Morgan LC, Chang AC. The global burden of respiratory infections in indigenous children and adults: a review. Respirology. 2017;22:1518-1528. doi:10.1111/resp.13131

21. Ospina MB, Voaklander DC, Stickland MK, King M, Senthilselvan A, Rowe BH. Prevalence of asthma and chronic obstructive pulmonary disease in aboriginal and non-aboriginal populations: a systematic review and meta-analysis of epidemiological studies. Can Respir J. 2012;19:355-360. doi:10.1155/2012/825107

22. Zhao Y, Connors C, Jo Wright J, Guthridge S, Bailie R. Estimating chronic disease prevalence among the remote aboriginal population of the Northern Territory using multiple data sources. Aust N Z J Public Health. 2008;32:307-313. doi:10.1111/j.1753-6405.2008.00245

23. Hoy WE, Davey RL, Sharma S, Hoy PW, Smith JM, Chennakesavan SK. Chronic disease profiles in remote aboriginal settings and implications for health services planning. Aust NZ J Public Health. 2010;34:11-18. doi:10.1111/j.1753-6405.2010.00467.x

24. Martínez-García MA, de la Rosa Carrillo D, Soler-Cataluña JJ, et al. Prognostic value of bronchiectasis in patients with moderate-tosevere chronic obstructive pulmonary disease. Am J Respir Crit Care Med. 2013;187:823-831. doi:10.1164/rccm.201208-1518OC

25. Martínez-García MÁ, Soler-Cataluña JJ, Donat Sanz Y, et al. Factors associated with bronchiectasis in patients with COPD. Chest. 2011;140:1130-1137. doi:10.1378/chest.10-1758

26. Kew KM, Seniukovich A. Inhaled steroids and risk of pneumonia for chronic obstructive pulmonary disease. Cochrane Database Syst Rev. 2014;3:Art. No.: CD010115. doi:10.1002/14651858.CD010115.pub2

27. Postma DS, Rabe KF. The asthma-COPD overlap syndrome. $N$ Engl $J$ Med. 2015;373:1241-1249. doi:10.1056/NEJMra1411863

28. Kauppi P, Kupiainen H, Lindqvist A, et al. Overlap syndrome of asthma and COPD predicts low quality of life. $J$ Asthma. 2011;48:279-285. doi:10.3109/02770903.2011.555576

29. Morgan AD, Zakeri R, Quint JK. Defining the relationship between COPD and CVD: what are the implications for clinical practice?. Ther Adv Respir Dis. 2018;12:1-16. doi:10.1177/1753465817750 524 
30. Bowman DMJS, Dingle JK, Johnston FH, Parry D, Foley M. Seasonal patterns in biomass smoke pollution and the mid-20thcentury transition from aboriginal to European fire management in northern Australia. Glob Ecol Biogeogr. 2007;16:246-256. doi:10.1111/geb.2007.16.issue-2

31. Bowman DM, Balch J, Artaxo P, et al. The human dimension of fire regimes on earth. J Biogeogr. 2011;38:2223-2236. doi:10.1111/ j.1365-2699.2011.02595.x

32. Vanderzalm JL, Hooper MA, Ryan B, et al. Impact of seasonal biomass burning on air quality in the 'top end' of regional Northern Australia. Clean Air Environ Qual. 2003;37:28-34

33. Franklin DC, Petty AM, Williamson GJ, Brook BW, Bowman DM. Monitoring contrasting land management in the savanna landscapes of northern Australia. Environ Manage. 2008;41:501-515. doi:10. 1007/s00267-007-9006-1

34. Whitehead PJ, Bowman DM, Preece N, Fraser F, Cooke P Customary use of fire by indigenous peoples in northern Australia: its contemporary role in savanna management. Int $J$ Wildland Fire. 2003;12:415-425. doi:10.1071/WF03027
35. Burgess CP, Johnston FH, Bowman DM, Whitehead PJ. Healthy country: healthy people? Exploring the health benefits of indigenous natural resource management. Aust $N Z J$ Public Health. 2005;29:117-122. doi:10.1111/j.1467-842X.2005.tb00060.x

36. Townsend M, Phillips R, Aldous D. "If the land is healthy ... it makes the people healthy": the relationship between caring for country and health for the yorta yorta nation, boonwurrung and bangerang tribes. Health Place. 2009;15:291-299. doi:10.1016/j.healthplace.2008.05.009

37. Bendall CL, Wilson DM, Frison KR, Inskip JA, Camp PG. A partnership for indigenous knowledge translation: implementation of a first nations community COPD screening day. Can J Respir Ther. 2016;52:105-109.

38. Navaratnam V, Forrester DL, Eg KP, Chang AB. paediatric and adult bronchiectasis: monitoring, cross-infection, role of multidisciplinary teams and self-management plans. Respirology. 2019;24:115-126. doi: $10.1111 /$ resp. 13451

\section{Publish your work in this journal}

The International Journal of COPD is an international, peer-reviewed journal of therapeutics and pharmacology focusing on concise rapid reporting of clinical studies and reviews in COPD. Special focus is given to the pathophysiological processes underlying the disease, intervention programs, patient focused education, and self management protocols. This journal is indexed on PubMed Central, MedLine and CAS. The manuscript management system is completely online and includes a very quick and fair peer-review system, which is all easy to use. Visit http://www.dovepress.com/testimonials.php to read real quotes from published authors. 